\title{
Music Video's Performing Bodies: Floria Sigismondi as Gestural Animator and Puppeteer
}

animation:

an interdisciplinary journal

$1-22$

(C) The Author(s) 2015

Reprints and permissions: sagepub.co.uk/journalsPermissions.nav DOI: I0.I|77/I7468477|5593697

anm.sagepub.com

@AGE

\section{Lisa Perrott}

The University of Waikato, New Zealand

\begin{abstract}
Auteur music video director Floria Sigismondi has a reputation for creating beautifully macabre imagery that has been described as surreal and uncanny. Less obvious is the way in which she uses animation and gesture to estrange the movement of performing bodies. While pixilation and stop motion animation are used together to invert the agency of humans and objects, Sigismondi's use of gesture extends this manipulation of agency beyond technical processes. This dialectic of cinematic agency is discussed through an examination of three music videos directed by Sigismondi: End of the World (2004) for The Cure, Montauk Fling (2013) for Lawrence Rothman and The Stars (Are Out Tonight) (2013) for David Bowie. Considering these videos in relation to puppet animation, live-action film and the cultural and historical migration of gesture, the author argues that Sigismondi puppetises humans and animates gesture as a means of transgression.
\end{abstract}

\section{Keywords}

animation, embodiment, Floria Sigismondi, gesture, human pixilation, music video, puppet animation, transgression, uncanny

After having wriggled, jerked, danced and flapped his arms like wings, David Bowie's body suddenly flops limply in time with the song's ending. He is like a marionette puppet that has been kept alive by an off-screen puppeteer, thus vivifying the music video for Little Wonder (1996). Having finished playing with her puppet, Sigismondi releases the strings and leaves him to droop lifelessly (see Figure 1).

Floria Sigismondi is a puppeteer. She gracefully and metaphorically manipulates strings as she animates performers' gesturing bodies and pioneers new approaches to music video. Having directed music videos for some of the most enduring figures of the music industry, Sigismondi has

\section{Corresponding author:}

Lisa Perrott, School of Arts, Screen \& Media programme, Faculty of Arts \& Social Sciences, Te Kura Kete Aronui, The University of Waikato, Private Bag 3105 , Hamilton 3240, New Zealand.

Email:Iperrott@waikato.ac.nz 


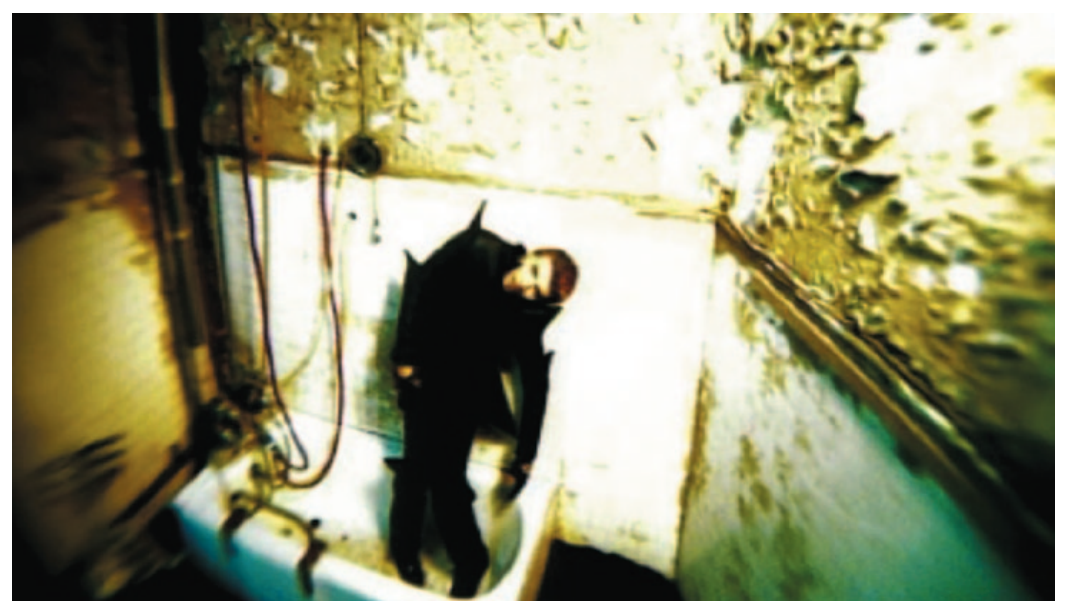

Figure I. [AQ: 2]

developed a formidable reputation as an auteur director who challenges audiences with her beautifully macabre imagery. Less obviously, Sigismondi could be viewed as an inheritor of Jan Švankmajer's animistic impulse. Citing Švankmajer and Stephen and Timothy Quay as exemplars of such an impulse, I argue that Sigismondi is a gestural animator who has developed a distinctively subversive strategy of puppetising humans. The uncanny aspect of human puppetry has provided a powerful metaphorical dimension to 'co-presence' puppet theatre ${ }^{1}$ as well as to feature films, and both of these performance forms serve as important resources for Sigismondi's music videos. Being John Malkovich (1999), directed by auteur music video director Spike Jonze, provides a pertinent cinematic example of puppetised humans. While kinaesthetically enticing viewers to identify with the experience of embodying and controlling another person, this film also works allegorically, raising philosophical questions about human agency and control in a neo-liberal capitalist society.

In order to understand the subversive potential of the puppet, it is necessary to explore the concept of the uncanny as it pertains to puppetry, object animation and pixilation. Through a close examination of three music videos directed by Sigismondi, I explore the richly gestural way in which she communicates kinaesthetically through bodies, arguing that her animation of gesture can be viewed as an act of transgression. My use of the term transgression is aligned with Bettina Papenburg and Marta Zarzycka (2013: 6), for whom transgressive imagery

... denotes the confounding of the boundary between ethics and aesthetics extending to the disruption of normative cultural frameworks and the breakthrough into new theoretical ground by way of exploring the performative potential of alternative perceptual modalities such as multisensorality, sensation and affectivity.

While this definition applies to carnal aesthetics associated with feminist politics, my use of the term transgression applies to the performative potential of animated music video to disrupt normative boundaries that constrain social and cultural practices associated with gendered, mediatised and embodied communication. In this context, transgression implies a deconstructive act of breaking rules and conventions in order to open the way for alternative ways of viewing, being, constructing and performing. 
My argument that Sigismondi directs as a gestural animator challenges received ideas about how broadly one can apply the conceptual parameters of animation. In my view, animation is a process of giving and transforming life, or movement, to non-living or inert matter, and to bodies and gestures. Animation derives from the Latin anima, meaning soul, spirit or breath and its derivative animism which attributes agency, life-force or soul to natural or material things. This understanding relates to Alan Cholodenko's (2014: 100) argument that 'animation film and film animation operate within, at, and beyond the limits of live action', and that 'theorizing of animation cannot limit itself to that endowing with life and motion but must consider the full cycles of each ... their metamorphoses, their diminutions, and their terminations - death and nonmotion - as well as their inextricable commingling throughout their cycles (p. 101, emphases added). The cycles of life and motion, death and nonmotion, are particularly relevant to my discussion of Sigismondi's work. While there is lively debate about the elasticity of Cholodenko's defining criteria, both elasticity and debate are necessary in order to push applications of animation theory into uncharted terrain. In contribution to Cholodenko's argument, my discussion of Sigismondi's work explicates a redefinition of animated agency through the process of gestural performativity. The fact that the process of animation may be obscure to many viewers of her work emphasizes the very nature of animation's transgressive capacity.

\section{Music video's bodies}

Since the emergence of music video as a televisual form in the 1970s, its production context has changed significantly. John Caldwell (2000: 135) explains how televisual aesthetics transformed during the 1980s and 1990s in response to technological advances in conjunction with cultural and ideational shifts driven by practitioners and audiences. While production technologies gradually became cheaper and more accessible, production values became more sophisticated. Televisuality shifted further towards a 'film-style look', which has undoubtedly influenced the work of many auteur music video directors. As with other media forms, the distribution of music video has shifted from television to the internet, where it is now experienced predominantly via Youtube, vimeo channels and viral media sharing. These changes have been accompanied by commercial instability associated with changes in the production and distribution of music. Despite such flux, music video has re-emerged as mutable, hybrid and unbound. The new distribution context, in conjunction with increased access to digital technology, has generated processes of democratisation and participatory culture. Music videos are now not only produced by professionals with large budgets, but also by amateurs and musicians with no budgets. The globalised cultural participation of audience-producers has given rise to innovations that have stretched and permeated the boundaries of music video (Vernallis, 2013). With an activated participatory culture, virally distributed media and a de-regulated exhibition context, the music video genre has undergone a precocious maturation process. The aesthetic and performative codes of music video have ripened to the point where intertextuality, performative mimicry and parody now proliferate (Railton and Watson, 2011). The social and cultural implications of this performativity are best understood when considering the audience experience of music video's performing bodies. In her book Unruly Media (2013), Carol Vernallis uses the term 'rhythmicize' to describe the particularly insistent way in which music video's performing bodies can kinaesthetically engage the body of the viewer:

Music video's bodies can exist in changeable, complicated spaces. Closely locked in, tethered to the performer's body, a viewer must navigate through rapid editing, changing speeds, and shifting scales ... The body is taken up by musical elements like a reiterating pulse ... This kinesthetic interpolation, driven 
by the music, a body's schema, a directed camera as well as unfolding space, remains more profound, insistent and consistent than the kinesthetic interpolation realized through many other media. (p. 159)

This kinaesthetic interpolation ${ }^{2}$ makes music video a fertile ground for the construction and transgression of normative images of the body. The use of animation may strengthen the transgressive capacity of music video, as has been demonstrated by the work of directors such as Chris Cunningham, Michel Gondry, Adam Jones and Sigismondi. Although each of these directors has developed identifiable auteurist trademarks, when taken together, their works are marked by a reflexive approach towards conventional music video, the animation of bodies and the construction of transgressive imagery. These directors challenge the audience to reflect upon the construction of the form, and to consider the role of music video in the performative construction of identity. They produce images of the body that destabilise preconceptions of the body as stable and autonomous. ${ }^{3}$

\section{Floria Sigismondi}

The directors mentioned above have helped to expand the conventional parameters of music video. While sharing some similarities with these directors, Sigismondi's work stands apart from them because of the unique way in which she animates. Her use of animation technique is comparatively sparse across her oeuvre, but her animation of gesture is a distinctive auterist trait, indicating a deep understanding of the relation between animation, still photography and human motion. Sigismondi's music videos are also distinctive for their cinematic virtuosity, which may have been prefigured due to her childhood exposure to opera and the opulence of theatrical sets and costumes. As an adult, her understanding of art history, painting and photography was developed through her art school education followed by her work as a fashion photographer (De Barros, SCENE 360b; Vernallis and Ueno, 2013). The professional step from still photography into directing music video enabled Sigismondi to explore the relationship between the still and moving image using a medium well suited to experimentation. Her videos demonstrate a painterly treatment of lighting and depth of field and a strong visual relationship with musical rhythm and timbre. Employing primarily liveaction shots, Sigismondi often straddles the space in-between stasis and motion.

Her work has become distinctive for the way in which it pushes beyond conventional expectations about what constitutes a music video. ${ }^{4}$ Incorporating intertextual references from photography, sculpture, silent film, avant-garde art and cinema, her music videos blur the boundaries between these forms. Working across a variety of media, she has explored themes such as gender ambiguity, beauty, alienation, death, vitalism and psychosis. When interviewed about her inclination to challenge notions of beauty, Sigismondi explained:

Beauty today has become so objectified, we are told what is beautiful, we are fed what is beautiful, we are sold what is beautiful ... Is desire what rules humans? And if so, what does that do to the human form? The female form, being a large object of desire, will be the more distorted one. (Sigismondi quoted in De Barros, SCENE 360a)

The animation of gesture provides a particularly suitable method for interrogating notions of beauty, enabling Sigismondi to create new life through the act of deconstruction: 'I'm also interested in deconstructing the body. And after you've taken it apart, the next step is to create a new one' (Sigismondi, quoted in SCENE 360b). One strategy of bodily deconstruction involves estranging the familiar by juxtaposing incongruous imagery in a way that confronts the viewer with a sense of unease. In her video for Montauk Fling (2013), a young woman's face is framed as an object of beauty. Her vacuous stare and painted face have a familiar but eerie association with a porcelain 


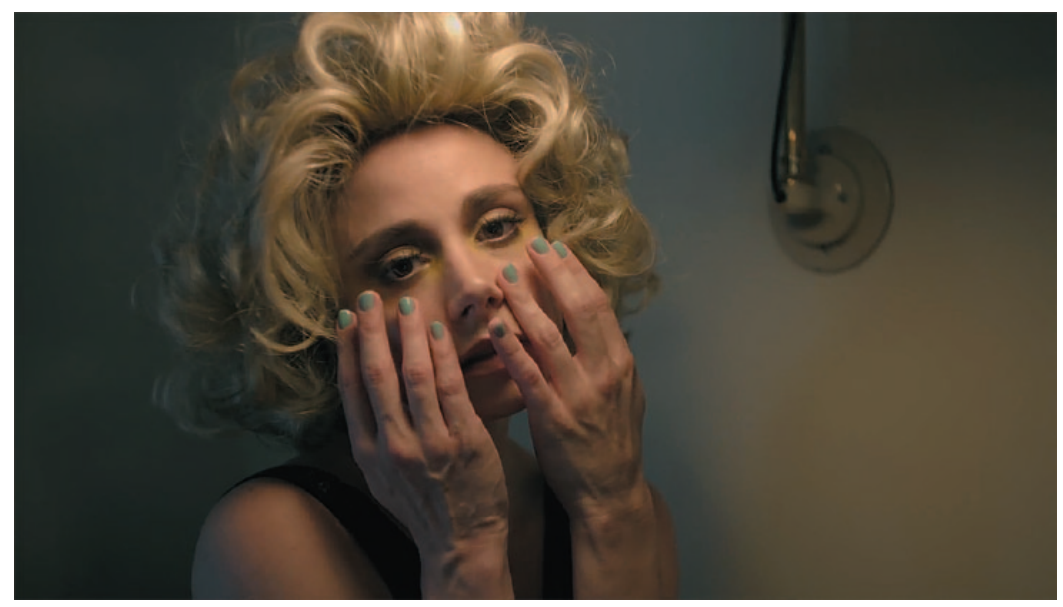

Figure 2. [AQ: 3]

doll. This 'beautiful doll' becomes defamiliarised when her hands move through the frame and it becomes apparent that these are the hands of an older, possibly masculine person (see Figure 2).

This defamiliarisation of the body can be understood in relation to the strategy of ostranenie ${ }^{5}$ as well as the surrealist concept of 'concrete irrationality', described by Laura Ivins-Hulley (2013: 270) as

... a meeting point between reality and imagination, where the boundaries between the two cannot be drawn. There is something recognizable but indescribable about it. It is composed of fragments of things that make sense, and yet the whole does not make sense, exposing the fragility of any system of organization.

These subversive strategies underpin the discomforting experience of Sigismondi's work. Populated by performing objects and puppetised humans interacting with strangely familiar other-worlds, her music videos embody a congruence of imagery that is simultaneously familiar and beautiful, yet strange and macabre. In order to understand this subversive imagery in a cultural and historical context, I have chosen to discuss three of her music videos in comparison to the work of filmmakers who have adopted similar strategies and whose films also provoke an uncanny experience for audience members. Czech filmmaker Jan Švankmajer's surrealist films The Flat (1968) and Food (1992) are particularly relevant for understanding the dialectic of cinematic agency that Sigismondi extends upon in her music videos. Influenced by Švankmajer's work, UK-based filmmakers Stephen and Timothy Quay are equally significant to comprehending the depth of Sigismondi's work. Their films Street of Crocodiles (1986), The Comb (1991) and The Sandman (2000) are relevant because of the way in which the Quays animate gesture through puppets and human characters. The 'mysterious gestural choreography' of their films reiterates and prefigures the negotiation of agency at play in the work of Švankmajer and Sigismondi (Crow, 2006: 52).

These strategies of defamiliarisation are supported by the way in which Sigismondi animates bodies in relation to objects and space. While using animation technique sparingly, Sigismondi applies her understanding of animation to infuse (and extract) life-force from performers, objects and spaces. In addition to her gestural direction, Sigismondi uses various cinematic strategies to alter the motion of the human characters depicted in her videos. Techniques such as pixilation, time-lapse photography, and speed-ramping serve to punctuate and momentarily disturb the viewer's perception of 'normal' human motion. 
The historical context in which these techniques were developed is particularly important for understanding the audience perception of animated time and the interstitial relationship between animation and cinema. Therefore it is pertinent to locate Sigismondi's cinematic manipulation of time and motion in relation to the foundational pre-cinematic work of Eadweard Muybridge. In his essay Muybridge's Magic Lantern, David Fresko (2013: 47) argues that Muybridge's 'animating interchange between stillness and motion' served to allay anxieties about photography's capacity to freeze bodily motion and capture time. Fresko explains that during the last few decades of the 19th century Muybridge operated as a travelling lecturer, presenting magic lantern shows in which he demonstrated the relationship between his still photographs of bodies frozen in motion with animated images of these bodies. These were set in motion using various precinematic technologies, such as the zoopraxiscope. ${ }^{6}$ Initially, his static photographs produced anxiety due to the lifelessness suggested by the freezing and fragmentation of bodily motion. The reason viewers perceived these fragments of motion as absurd, and the role of cinematic motion in allaying this anxiety is clarified by Laura Mulvey (2006: 15): 'The photographic freezing of reality ... marks a transition from the animate to the inanimate, from life to death. The cinema reverses this process by means of an illusion that animates the inanimate frames of its origin.' By fragmenting human motion into increments of discontinuous time, Sigismondi, like Muybridge, renders the animate as inanimate, thus alluding to death and alienating the human body. But while Muybridge used animation to diminish this alienating affect so that viewers would perceive bodily motion as natural, Sigismondi has used animation methods such as pixilation to make human motion appear unnatural.

\section{Pixilation, object-ification, animism}

Pixilation is a stop motion animation technique that records human motion by capturing individual frames on either side of a fragment of movement. The duration of each fragment might be a fraction of a second or it could be a few seconds long. Occurring in-between the captured frames, the movement fragment is not visible in the completed film. It is the absence of this section of movement that alters the way audience members will perceive the motion of human performers, including anything moving within the on-screen space. While stop motion is often used to give life to objects, the same process applied to human subjects tends to produce a dehumanising effect, rendering humans much like objects. Depending on how many frames are shot per second and the amount of movement in-between frames, the motion of the pixilated body can appear subtly abnormal or it can be noticeably jerky and mechanised. This dehumanising affect can be intensified by combining the pixilation of humans with the stop animation of objects or puppets, as is the case with the music video for Radiohead's song There There (2003) directed by Chris Hopewell, and Švankmajer's short films Food (1992) and The Flat (1968), which are discussed below. ${ }^{7}$

Švankmajer's philosophical approach provides a fitting frame through which to consider the ontological ambiguity induced by Sigismondi's treatment of objects as subjects and vice versa. Švankmajer's embrace of animism informs the way he animates objects as well as how he thinks about objects in relation to humans:

To my eyes, objects have always been livelier than human beings. More static but also more telling. More moving because of their concealed meanings and their memory, which beats human memory. Objects are keepers of the events they have witnessed ... In my films, I have always tried to extract content from the objects. To listen to and to put their stories into images. (Švankmajer, cited in Furniss, 1998: 171)

Viewing everyday objects as possessing a life-force or soul, Švankmajer takes this idea even further by imagining what objects might do with the historical and cultural memories they acquire 
over time. This imagining is played out in several of his films. In The Flat (1968), familiar everyday objects such as a chair and a fork are stop animated, enlivening their latent agency and enabling them to rebel against the humans who have taken them for granted over the years. Švankmajer explains his approach to object animation as a subversive strategy:

Animation enables me to give magical powers to things. In my films, I move many objects, real objects. Suddenly, everyday contact with things which people are used to acquires a new dimension and in this way casts a doubt over reality. In other words, I use animation as a means of subversion. (Švankmajer, quoted in Wells, 1998: 11)

Aligned with the objectives of the Czech and Slovak Surrealist group, Švankmajer's empowerment of familiar objects is a subversive strategy that induces in audience members a state of ontological ambiguity (Cardinal, 1995). This phenomenon becomes even more complex when considered in relation to Švankmajer's animation of human characters, as is the case in his three-part film Food (1992). In part one of this film, human actors perform as vending machines that are activated when money is inserted into their mouths. The pixilated movement of their bodies accentuates their performance as mechanised objects, thus supporting an allegory of a dehumanised society controlled by commerce. Through her discussion of Food, Ivins-Hulley (2013: 268) explains how pixilation plays an important role in Švankmajer's treatment of human actors as objects:

... through this technique, the director 'object-ifies' the actors, paradoxically taking away much of their human agency even as he so often grants agency to non-living objects through stop motion ... Švankmajer undermines the self-coherence and autonomy of the human body, and ... his films foreground how physical utterances construct human agency. The animated bodies in Food - which enact stop motion's dialectic between stasis and movement in a manner unique to pixilation - are abject bodies that expose the boundaries of embodied agency.

The paradox of animism and human object-ification observed at play in Švankmajer's films is similarly manifest in Sigismondi's music videos. This is exemplified in her music video for The Cure's song End of the World (2004), where a sense of the uncanny body is produced by the pixilated representation of Robert Smith's movement, in conjunction with the stop animation of objects. While Smith has the appearance of a live-action performer, his movement feels slightly abnormal. His body appears alienated as he tentatively moves around the house, which is in keeping with his gothic persona. With porcelain foundation, dark eyeliner and lipstick, he performs as an ambiguously gendered gothic doll, who is victimised by his home and contents' psychic will to self-destruct, thereby enabling plant life to regenerate.

Brought to life by stop animation, a small doll resembling Smith climbs onto the table to accompany him as he sings. Sitting down on the table-top, the doll watches as a milk jug and sugar jar pour their contents off the edge of the table. The sugar runs along the floor and out through a mouse-hole in the skirting board. This revolt of household objects spreads throughout the house, as though infecting the animistic 'spirit' of the house. The kitchen sink is full of dirty crockery that breaks into small pieces when the taps turn on. Reaching into the fridge to grab an apple, both the apple and Smith's hand become encased in a block of ice. As the ice melts, Smith's coffee cup and spoon dance around the table. The chairs come to life, tumbling out of frame before knocking a hole in the wall. The hole grows bigger, the table legs collapse and the table top breaks up on the floor. Books re-arrange themselves into higher and lower piles in co-ordination with the music. Toothpaste squeezes itself from its tube and a toothbrush shuffles around the sink, applying the toothpaste to its bristles. Smith writhes around in his bed as though experiencing a nightmare he has no control over. The bedcovers slip off the bed, crawling up the walls and the wallpaper peels 


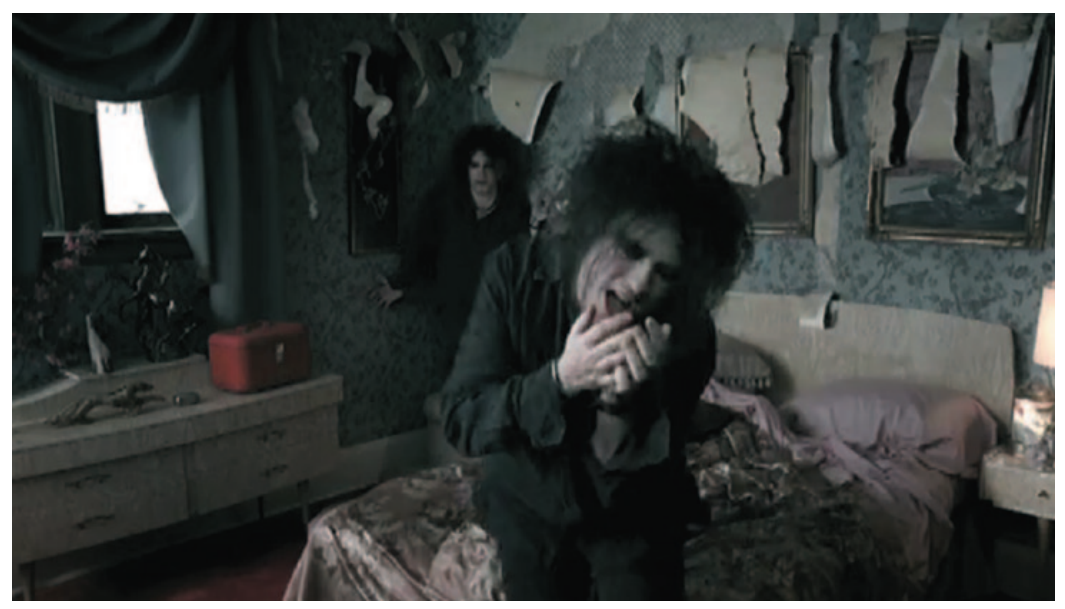

Figure 3. [AQ: 4]

itself off in large torn strips (see Figure 3). Smith's gesturing body is passive and eventually powerless to stop the destruction of his home. He has less life-force than the objects and space encompassing him, which possess the agency of self-destruction - a scenario similar to the inverted agency enabling objects to torment the human character in The Flat.

In addition to Švankmajer's animistic impulse, Aylish Wood's article Re-animating space (2006) is useful here as a means of understanding how animation's re-invigoration of spatial elements activates the latent gestural agency of objects.

At first glance, this seems like a novel idea for a music video with a dystopian theme. But Sigismondi's use of animation goes beyond novelty, leading her to estrange the audience's 'normal' perception of bodily movement and its relation to space, thus alluding to allegories of power and control. While pixilation extracts life-like motion from Smith's body, stop animation gives life to objects and agency to the space surrounding his body. This produces an inverted power relationship between the performer's body and the domestic space of the home. This star performer's powerlessness in the face of an apocalyptic domicile seems ironic within a media context saturated by DIY reality television, where everyday people have the agency to build their dream home, to have control over the objects in their domestic environment and to become 'stars' in the process.

End of the World exemplifies how Sigismondi's inversion of human agency bears similarity to Švankmajer's paradoxical treatment of human agency in Food and The Flat, films which also use inverted agency to allegorically subvert broader societal structures of power and control. Švankmajer's philosophical approach helps us to understand the abject quality of Sigismondi's work, and to consider the possibility that she may also be motivated by an animistic impulse in her use of surrealist strategies. Both directors puppetise and object-ify their human performers, defamiliarising their bodily motion in order to communicate a deficit of human agency which is both kinaesthetically experienced and allegorical. Both directors use a complex mix of media, cinematography and animation techniques and both slip ambiguously between sequences that are pixilated and those that are shot using live-action cinematography.

In comparison to the salience of object animation and pixilation in Švankmajer's films, most of Sigismondi's music videos are comprised predominantly of live-action shots, with usually only small sequences being technically animated using stop-motion or pixilation. Most interesting though is how her paradox of human object-ification manifests in her direction of non-pixilated live-action performers, such as in her video Montaug Fling (2013) as discussed below. 


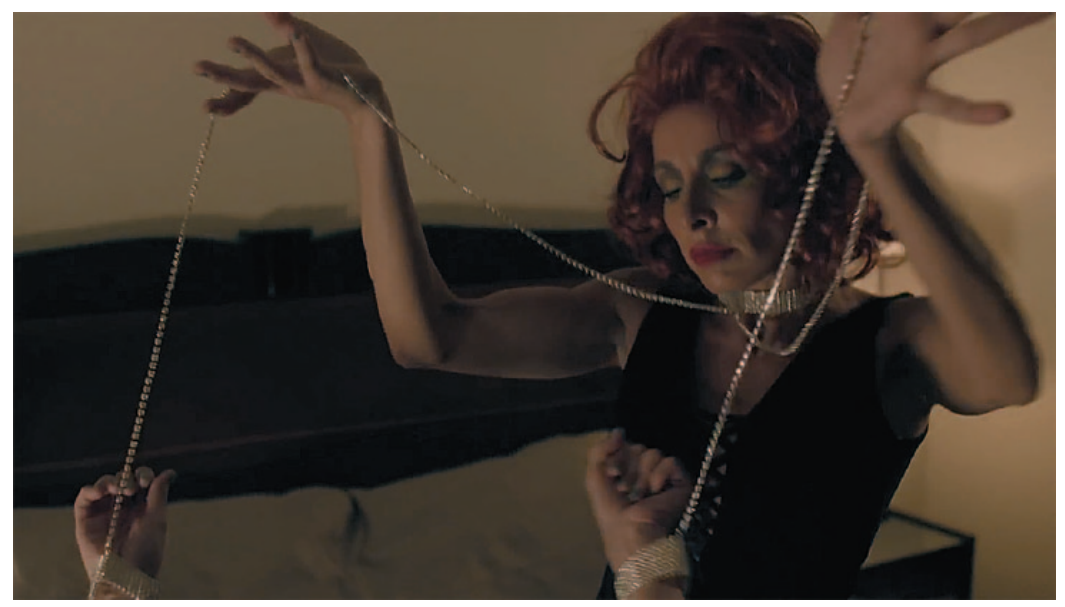

Figure 4. [AQ: 5]

Considering the perceived stability of screen performers bodies, Ivins-Hulley (2013: 271) proposes that 'Pixilation creates unstable bodies, reveals that character is always constructed, and introduces a dialectic of cinematic agency between the actors on the one side and the director and the animator on the other.' In other words, pixilation challenges the perception that the human body is stable, autonomous and in control. The technical process of pixilation does not simply extract agency from actors. Agency can be viewed as a contestable resource - an energy resource that may be pulled backwards and forwards, dynamically and inequitably controlled by either the actor, animator or director. Sigismondi extends this dialectic of cinematic agency beyond the technical parameters of pixilation, a process which is exemplified in her music video for Lawrence Rothman's song Montauk Fling (2013).

Responding to the cinematic quality of Rothman's music, Sigismondi conceived the video for Montauk Fling as a melding of intertextual references and gestures derived from cinema. The entire video is set within the Chateau Marmont Hotel, which embodies a notorious cultural memory, accrued over time through stories of misbehaviour and substance abuse by celebrities who resided there. Delving into the psychosis of celebrity culture, Sigismondi cast Rothman as a 'deranged Elizabeth Taylor' who is stuck, as she describes it, in a 'tragic parallel reality where the character's hunger descends into madness' (Nowness.com, 2013). Acting out their part in a 'messy love triangle', dancers Bridgette Hackman and Linda Borini were choreographed on set, performing a mixture of semi-synchronous movements that detourne the gestural objectification proliferating contemporary popular music video. ${ }^{8}$

As mentioned earlier, one of the ways in which Sigismondi puppetises her performers is by extending the dialectic of cinematic agency beyond the technical parameters of pixilation. Although the dancers in Montauk Fling are not technically pixilated, their movement is so intricately directed that it resembles some characteristics of pixilated performance. Occurring in highly controlled incremental steps, their movement appears devivified and puppetised.

In one sequence, the dancers are on a bed controlling each other's movements with long necklaces that connect to wrist and neck collars (see Figure 4). These necklaces are suggestive of marionette strings, an association which is accentuated by the negotiation of agency portrayed by their bedtop dance. This suggestion of marionette strings segues into the next sequence, where the dancers brace themselves against the walls of the hallway as they move like marionette puppets, 


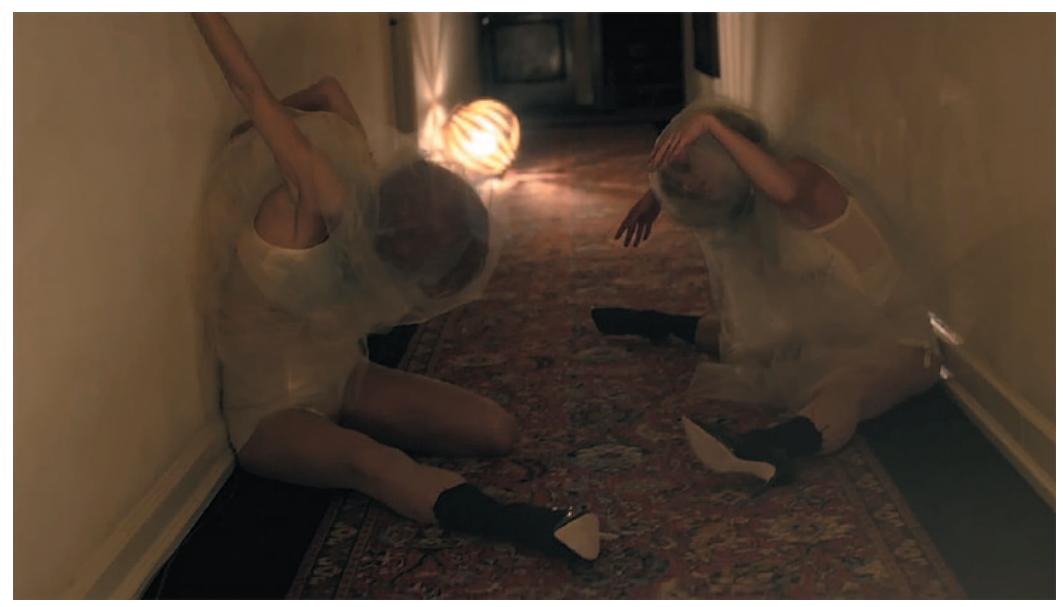

\section{Figure 5. [AQ: 6]}

incrementally and awkwardly to a seated position on the floor. One of the dancers sits with her legs woodenly placed at right angles, her arms rigidly bent at the elbows, hands drooping from the wrists, with her head cocked to one side. The other dancer droops her head as though in response to a puppeteer relinquishing control of the head-string (see Figure 5).

In other sequences, these dancers appear more like mannequins - adopting still poses as though they have been placed in a display window. The combination of posed and incremental movement creates a heightened sense of the space between stasis and motion - much like pixilation does. As her work straddles the still image, the moving image and three-dimensional sculpture, Sigismondi constantly negotiates the space between stasis and motion, particularly as it pertains to the gesturing body.

Sigismondi may puppetise her human performers through pixilation as well as her intricate directorial control over their movements. But the physical motion of their bodies is not fabricated, and they still exercise varying degrees of agency. Accentuated by the god-like presence of 'star' performers, viewers must negotiate the tension created upon experiencing these constructed, fluid characters performing through malleable, unstable bodies. This constantly shifting uncertainty about the recognition of a performer as subject or object manifests itself in an uncanny experience for the audience - a phenomenon that has been well understood by those engaged in object theatre and the performance of puppets. ${ }^{9}$

\section{Uncanny puppets}

According to Ernst Jentsch (1995[1906]), the underlying cause of 'the uncanny feeling' derives from uncertainty over the degree to which something appears animate or not. Crucially for Jentsch, this doubt often manifests as an obscure subconscious feeling, rather than a cognitive awareness. Puppeteer and theatre historian John Bell (2014: 46) explains how Jentsch and Sigmund Freud's articles represented the uncanny in a pathological sense, so that the 'animism attached to puppets, masks and performing objects thus becomes a problem of modernity', making it difficult to understand the 'communicative powers' of performing objects outside the frame of pathology: 'Their concept of the uncanny defines the power of objects as a problem, not a window into the nature of the material world and its agency.' 
Jentsch and Freud laid the foundations for much of the contemporary discourse about the uncanny as pathological and problematic. Academic researchers and software developers currently put much effort into determining the triggers for uncanny responses, and to developing software aimed at eventually eliminating the possibility that media products might trigger uncanny responses (Tinwell, 2014). Computer animators and game developers who follow the quest to perfect digital realism argue that the 'uncanny valley' obstructs empathetic identification with computer-generated 'puppets'. ${ }^{10}$ As argued by Bell (2014: 49), realism and rationality are elevated at the expense of a vitalist engagement with objects. Modern society attempts to control 'the animate nature of objects' by using the concept of the uncanny in a pathological sense 'rather than to consider the disconcerting possibility of the agency of things'.

While there exists an intrinsic connection between animism and the uncanny, a disregard for the latter can undermine the material experience and creative potential of the former. ${ }^{11}$ In the face of the current energy put towards avoiding the potential of uncanny responses to media products, the puppets and performing objects directed by Švankmajer and Sigismondi subvert this compulsion. Through the movement of their performers' bodies, they communicate a metaphysical act of transgression by liberating their animate nature - thus activating Bell's (2014: 49) idea that the 'uncanny is a force that tugs back on the civilizing and rationalizing thrust of modern thinking.' In their refusal to tame this uncanny force, these directors are fully aware that their work will be experienced with varying degrees of abject discomfort. Acts of transgression performed by puppets induce anxiety due to their ontological ambiguity and because their movement suggests a submission of human control to an external force. The performing objects, mannequins, dolls and human puppets populating Sigismondi's videos serve as reminders of the limitations of our own potential to control the material world in which we live. They are also suggestive of the potential for the most basic control over bodily movement being in the hands of an external agent. The reoccurring presence of dolls in her videos plays a significant part in evoking an uncanny response. According to Eva-Maria Simms (1996: 8), 'the doll is a harbinger of the death principle in Rilke's work ... her unresponsiveness supports and destroys the imaginative reality of the child's play ... The doll is a dead body, an inanimate child, an unresponsive, rigid corpse.' Whether through the presence of actual dolls, or humans who are directed to perform as dolls, Sigismondi frequently reminds us that we will all eventually end up as lifeless objects. This reminder is dealt to us through puppetisation in the final image of Little Wonder (1996), where Bowie ends up hanging limply as a lifeless object (see Figure 1), and also by the dancers in Montauk Fling (2013), due to their incremental movement as well as their associations with porcelain dolls and shop mannequins.

Montauk Fling's human mannequins are surreal in the sense that Buchan describes the Quays' puppets as 'modern mannequins, with the status of both intimate and alien' (Foster, quoted in Buchan, 2011: 110). Their intimacy lies in their mortal flesh and the vulnerable quality of their unsteady movement. But the ontological ambiguity of these teetering human dolls makes them alien. Their controlled poses, vacuous stares and wigs are strongly reminiscent of partially denuded mannequins, entombed within store windows for all to see in various states of undress (see Figure 6). Montauk Fling's human mannequins are reminiscent of the animated mannequins in Jiri Barta's short film The Club of the Laid Off (1989), in which life-sized shop mannequins are brought to life using stop motion animation. The mannequins perform a seemingly predetermined cycle of repetitive actions and hysterical gestures, suggesting an allegory of societal objectification and a disposable attitude towards human and material value. Controlled, trapped and on round-the-clock display, the shop mannequin is a potent symbol of the power relation between the owner of the gaze and the object of the gaze. Ironically, the object-ification of Montauk Fling's bodies is subversive as it invites us to identify with the experience of being object-ified. Rendered as objects in the form of life-like dolls, the dancers hover on the brink of life and death. 


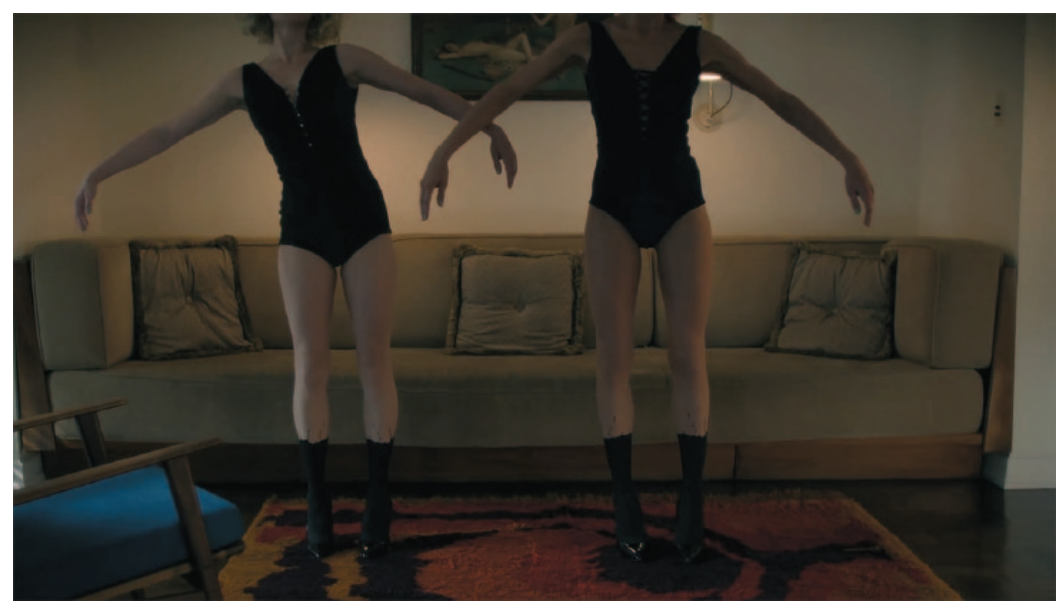

Figure 6. [AQ: 7$]$

\section{Gesture}

Whether through puppetry or human performance, gesture is a primary (and primal) means by which the animate nature of objects and the human body are communicated. Gesture is also a signifying system by which humans and puppets communicate volition and agency, where the capacity of puppets to perform human-like gestures can endow them with the appearance of sentient beings. Considering the capacity of empathetic engagement with the puppets animated by the Quay Brothers, Suzanne Buchan (2011: 117) explains the emotional affect of gesture. The Quay puppets are:

... imbued with an animistic force - on the one hand through the cinematic illusion of the animation technique, and on the other by the emotionally underpinned movements and gestures that the Quays add incrementally while filming, which, in screening, suggests a form of sentience.

This illusion that the Quay puppets experience emotion is constructed by gestures such as 'a hand sensuously stroking a moist kidney or caressing a slab of liver' (p. 126) as in Street of Crocodiles (1986). For the viewer, a sense of identification and empathy is assisted by sentient gestures such as a nurturing touch or a puppet gazing upon another. This is also a facet of 'co-presence' in puppet theatre, where the gaze functions as a sign of a puppet's consciousness, especially when the puppet's gaze meets that of its human puppeteer-performer (Piris, 2014). Conversely, human performers whose gestures are lacking or devoid of sentience may appear dehumanised and more like objects, dolls, or puppets, abdicating power to a puppeteer - as exemplified by the dancers in Montauk Fling. ${ }^{12}$

While not always consciously registered, gestures such as gazing and stroking have a powerful effect when we see them performed on screen. Our bodies recognise them kinaesthetically due to our embodied memory. Transmitted directly from one body to another, gesture is a sign system that has the ability to bypass cognitive process and linguistic translation (Rotman, 2008). Since gesture is communicated affectively by and through bodies, it serves a different purpose to linguistic communication. We do not need to think about a gesture as it is performed, but as theorised by Giles Deleuze, we cannot help but experience its intensity and imminence (Colman, 2011). 
Gestures may appear as though they are idiosyncratic expressions, originating from within autonomous beings. Although an individual might connect gestures syntactically, shape and express them in new ways, gestures are not owned by individuals. They are socially and culturally distributed resources that accrue meaning through repetitive performance. Destroying any illusion that they might be possessed by individuals, Lesley Stern (2002: 7) describes gestures like 'wandering homeless ghosts [that] take up residence in alien bodies, there to play out the repetition that is their destiny'. This spectral metaphor is particularly appropriate for examining the evocational way in which Sigismondi appears to summon gestures from a multitude of sources, and transmute them through performing bodies. ${ }^{13}$ Her experience as a fashion photographer is likely to have provided a rich repository of gestures associated with the display of the body as an object, and these gestures support the object-ification of the dancers in Montauk Fling. ${ }^{14}$ Through their bodies, Sigismondi has articulated gestures from fashion photography together with those derived from cinema, puppet performance, shop mannequins and dance. This gestural mix, performed against a highly stylised set, shares similarities with the filmic references and performativity of Cindy Sherman's photography. ${ }^{15}$ The overall sense that the dancers are objects on display is accentuated by the set design, lingerie costumes, make-up and 'ink-dipped' legs (see Figures 5 and 6).

At the risk of overplaying Sigismondi's agency to pick-and-mix gestures at will, her penchant gestural articulation must be contextualised. As with other directors, Sigismondi is only one agent within a broader process of gestural circulation, in which the migration of gestures makes them enduring and malleable:

The interesting thing about the gestural as it manifests cinematically is its propensity for migration. Gestures migrate from one movie to another, from the movies into social milieux and vice versa, they resonate, disappear and reappear - differently, and the differences pertain to cultural and historical context as well as media and genre. (Stern, 2002: 1)

Although Stern's notion of a gestural circuit pertains primarily to cinema, it is useful to consider such a circuit as intermedial and interdisciplinary and to view gestures as migrating intertextually through films, music videos, fashion, photography, dance and theatrical performances. The transgressive potential of gesture derives in part from its reiteration, but also from its transformation as it traverses media forms, bodies, cultural and historical boundaries (Noland, 2009).

Stern's metaphor of gestures as wandering ghosts provides a tangible way of imagining the transient and mutable iteration of gesture in music video. In this form, gesture's partnership with the timbre, rhythmic, melodic and lyrical components of music can also be configured as a form of dance. In this musically led dance, gesture has most saliently functioned to communicate the vitality, exuberance and agency of star performers, who have been 'foregrounded in bold relief [where] the camera showcases every curl of the fingertips, and bend of the elbow, every wrinkle of the brow and blink of the eyelid' (Vernallis, 2004: 54). This gestural fetishisation might seem to be an obvious function of music video, where the detailed scrutiny and hyperbolisation of gesture constructs an effigy for the deification of star performers. But music video's repetitive performativity of gesture (and of gender) in the form of bodily 'statements' and dance moves is often taken for granted as being a commonsense visual companion to the music.

As demonstrated in Montauk Fling, Sigismondi imbues her performers with a unique dancerly approach to embodied expression, where bodily movements can appear simultaneously graceful, ambiguously gendered, erotic, and abjectly uncomfortable. However, her work is most disturbingly memorable in the way in which she uses gesture to communicate not only the animate nature of objects, but a state in which humans are in-animate and devivified. In both of these situations, gesture plays a key role in affectively provoking a sense of the uncanny. In Gesturing toward 
Olympia, Heather Crow (2006: 58) explores the 'gestural uncanny' through a discussion of two films directed by the Quay Brothers. These films are relevant to Sigismondi's work because both involve primary characters that are dehumanised primarily through gesture. In The Sandman (2000), the automaton body of Olympia is alienated somewhere in between life and death due to a 'gestural choreography of (im)mobility and (de)animation'. ${ }^{16}$ And in The Comb (1991), the human 'Sleeping Beauty' performs 'hysterical gestures' ${ }^{17}$ which are analogically echoed by an animated doll. Both films exemplify Crow's point that 'gesture itself is uncanny - a performative enactment of the slipperiness of boundaries and the ambivalence of moving bodies' (p. 50). Pointing to the subversive implications of animating bodies, Crow explains that 'the gestural uncanny designates the instability and ambivalence of the body in motion, turned inside-out and outside in by (un) familiar corporeal articulations embraced as constitutive of embodied identity' (p. 50). Crow's discussion of how bodies are animated by gesture provides a particularly useful context for considering Sigismondi's directorial practice as a gestural animator. By animating her performers' bodies through pixilation and puppetisation, their gestural movement becomes defamiliarised and their bodies are captured in a spectral space, somewhere in-between motion and stasis, living and nonliving. As Crow observes, the 'gesturing bodies' in the Quay's puppet films are 'like ghosts - trembling on the border between life and death' (p. 52). The 'animated world of the Quays' is 'full of ghosts, life in things that ought to be dead' (Marks, quoted in Crow, 2006: 52). Inversely, the world evoked by Montauk Fling is full of ghosts, death in bodies that ought to be alive. While the ghost of Elizabeth Taylor is re-animated through the gesturing body of Rothman in drag, the dancers are also like ghosts as they teeter on the border between living humans and non-living objects. According to Sigismondi, these performers 'ended up drawing a little upon the spirit of the Chateau ... like haunted spirits roaming its halls’ (Nowness.com, 2013).

\section{Performativity of gender and gesture}

In music video, gesture plays a significant role in the process Judith Butler (1990: 137) has described as performative 'drag'. Butler uses this term, not simply to imply the imitation of gender through costume and make-up, but to describe the construction, normalisation and transgression of gender through repetitive acts of mimetic performance. Carrie Noland (2009: 185) explains how gestural performance plays a powerful role in this process, where its propensity for alteration and kinaesthetic re-experience provide the conditions for resistance:

... resistance appears to arise from two interlocking phenomena: first, the subject's dispersal into numerous enunciative positions, that is, numerous performatives (and thus the possibility of recombining verbal or gestural chains), and second, the necessity to repeat performative acts (and thus the possibility in the course of the performance of inflecting them in unpredictable ways).

Noland explains this reconfiguration of gesture in relation to rule breaking, where 'iteration within or without the conventional context' forms a dangerous 'condition of potential detournement' (p. 185). By deconstructing the human subject and reconfiguring gesture in unexpected ways, Sigismondi forms the conditions for potential detournement, as exemplified by the puppetised reconfiguration of dancers' movement and by Rothman's drag performance in Montauk Fling.

Just as Butler (1990: 140) theorised the performative repetition of gender, the performative repetition of gesture is mediated by social and cultural contexts. In the case of animated music video, gesture is mediated by such things as the performance of the actor, cinematic techniques, and the director's role in animating the gestural performance of the actor's body. In this process, the animator can be understood as not only acting through, but gesturing through the body 
of the actor (Buchan, 2011: 107). Summoning the gestural resources available to her, Sigismondi transmutes them through the bodies of her puppetised performers, characterising their motion variously as victimised, distilled, theatrically exaggerated, energised, devivified, hysterical or opiated.

Costume and make-up are important gestural resources supporting Rothman's drag performance of Elizabeth Taylor, where these adornments create a mask of glamour and femininity. But this mask is complicated by his gesturing body, which gradually confronts the viewer with a sense of uncertainty due to the ambivalence of its gendered movement. Having closely studied Who's Afraid of Virginia Woolf (1966), Rothman embodies the languid instability that characterises Taylor's performance in this film. Emulating her inebriated demeanour, his movement has an opiated quality as he stabilises himself against the walls and drags himself along the floor. His masculine physique is estranged by his hand and arm gesticulations, which communicate feminine power. While resembling Taylor's bodily performance, these gestures are also suggestive of those depicted in Dracula (1992), another film studied by Rothman in preparation for his performance. ${ }^{18}$

Considering this interweaving of intertextual film references, it is helpful to consider gestural performance in relation to film production, where the 'performing body' can be conceived of as multiple, non-human - even as a technical apparatus. As an extension to Vivian Sobchack's (1992) notion of the 'film's body', the music video director can also be understood as gesturing through the 'music-video body'. This idea is closely related to Laleen Jayamanne's concept of filmic performance, where:

In film the lighting, editing, camera distance, and movement are equally potent 'performers,' so that one could talk of filmic performance as including all these technical elements. These elements can transform the phenomenal body to such an extent that one could say the body that cinema materialises did not exist prior to the invention of film. (Jayamanne, quoted in Brannigan, 2011: viii)

In this light, many of Sigismondi's 'auteur trademarks' can be understood as an idiosyncratic approach to gesturing by use of her cinematic tools. While this process is further mediated by a cinematographer, editor, costume or set designer, it is possible to consider the strength of this auteurial gesturing process when examining her cinematic trademarks. Sigismondi has articulated and transmuted gestures through her performers' bodies, as well as through the lighting, cinematography, set design, costume and make-up. In Montauk Fling the combination of slow-motion and hand-held camera in some sequences adds to the sense of psychological instability generated by Rothman's gestural performance. The shadows against the walls, veiled faces, windblown sheer curtains, bloodthirsty gaping mouths and silent screams are cinematic gestures that have been reiterated in vampire films such as Dracula. The vampire is also suggested by the ambiguity of the lipstick (or blood) smears on the mirror and dancers' faces. Lipstick smearing has been repetitively performed as an act of subversion associated with performative drag, ${ }^{19}$ and has signified unstable psychological states in cinema. The combined use of the mirror and facial lipstick smearing in Montauk Fling is strongly reminiscent of prominent lipstick scenes in Wild at Heart (1990) and Blue Velvet (1986). In these films, director David Lynch utilises the smudging, smearing and transference of lipstick as a gestural signifier of psychological instability, which is reiterated by Sigismondi to signify the unstable underbelly of Hollywood celebrity culture.

The spirit of the hotel is evoked by the gestural performance of the actors in collaboration with the music, cinematography, lighting and set design. Along with her actors and production team, Sigismondi has drawn out the cultural memory embodied in the space and décor of the hotel. With her animistic approach to the life-force existing in objects and space, Sigismondi has re-animated 


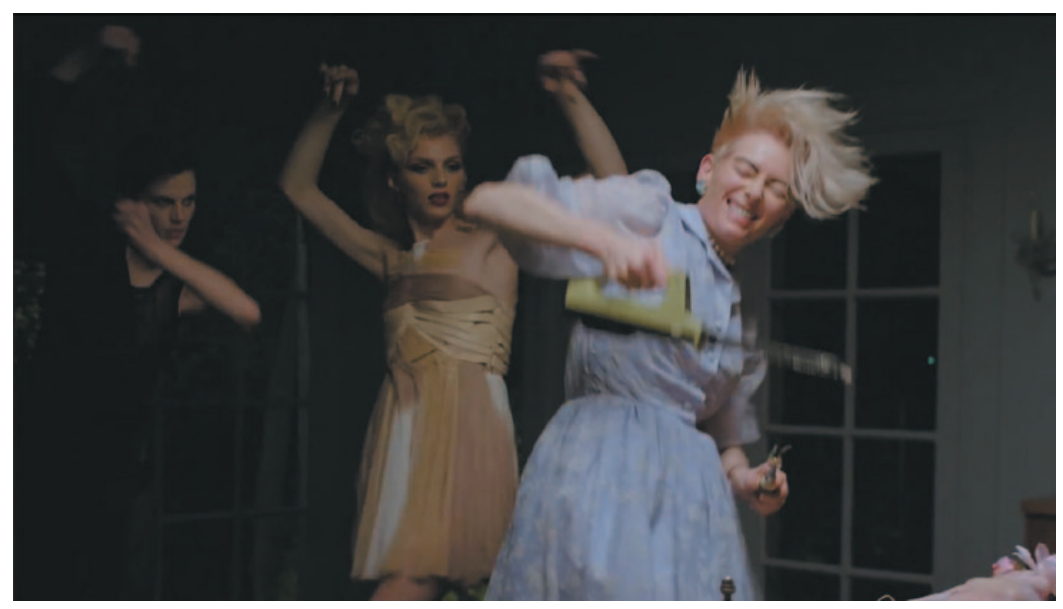

Figure 7. [AQ: 8]

and liberated the spectral presence that exists within the Chateau Marmont. Once again she is playing with ontological ambiguity and the paradoxical inversion of life-force - while she strips agency from her human performers, the spectral presence residing in the Chateu Marmont is brought to life as the most active agent in this music video.

\section{Shifting agencies}

Erin Brannigan (2011: 63) defines the gestural language of cinema, as a "medial modality that emerged in the early years of narrative film from a confluence of performance and cinematic technologies' [AQ: 1]. While Brannigan is concerned with dance film's re-animation of early cinema's gestural language, her definition can be applied to Sigismondi's music videos, where performance can be viewed as a confluence of gestural acts by the shifting agencies of the various performers. ${ }^{20}$

In her video for Bowie's song The Stars (Are Out Tonight) (2013), Sigismondi's animation of the performers' bodies functions as a narrative device that communicates shifting states of psychic control. Bowie spends much of the video being haunted by the ghostly presence of his past personas and harassed by the adherence of two androgenous models who goad him with their sycophantic behaviour. ${ }^{21}$ Unlike the human motion in End of The World and Montauk Fling, Bowie's body movement in The Stars projects a comparatively high degree of self control and does not appear abnormal until his agency shifts at the end of the video. Pixilation and speed-ramping are used to alter the motion of the two models, whose jerky movement suggests they may be possessed by a divine creature or off-screen agent. The same cinematic manipulation of movement is used to show a shift in the character of Bowie's wife, played by Tilda Swinton. This shift occurs when one of the models takes on the form of a succubus, hovering above Bowie in his sleep. While Bowie appears unaffected by this attempt to seduce him, his wife becomes possessed, and this is indicated by her estranged movement and maniacal gestures. She writhes feverishly on the bed, emulating the movement of the succubus writhing under her bed. Later at the dinner table, her head and arms jerk spasmodically while Bowie watches with concern at his wife's apparent loss of control. Waving an electric knife in a frenzy, Swinton carves up a raw chicken carcase on the dinner table, then joins the models as they jerk towards Bowie like zombies moving in to take his soul (see Figure 7). By the end of the video a transformation has taken place. The models have swapped lives with Bowie and his wife, and all four characters are pixilated as they pose before the camera. 
The estranged body movement of Swinton and the models is suggestive of evil spirits taking control of the human soul. The hysterical quality of their movement is also reminiscent of the gestural body motion associated with the films of the silent era. Many of these films were shot at a slower frame rate than they were projected at, resulting in the motion of actors appearing unnaturally jerky and speeded-up. The characteristic bodily motion of this era has been described by Jonathan Auerbach (2007: 11) as an expression of the gesture of hysteria:

... figures in these early films seem possessed, at the mercy of mysterious powerful forces, unseen but felt, beyond personal control; they are seized by fits of near hysteria ... or insanity ... or governed by gravity ... or nervous electrical impulses ... suggesting how neither filmmakers nor viewers nor bodies on-screen quite knew what to make of or do with themselves.

Auerbach's characterisation of the gesture of hysteria in silent cinema is relevant to the animated figures in The Stars, where the perception of lost personal control is achieved by pixilation, careful manipulation of alternating frame rates and the performance of gestures associated with hysteria. According to Crow (2006: 53), such gestures include 'tics, grimaces, epileptoid convulsions and mechanical, seemingly involuntary movements of the limb or torso'. Crow explains how in The Comb (1990) 'hysterical gestures' provide continuity between animated puppets and human liveaction footage, where 'embodiment itself becomes fraught with anxiety, becomes a kind of madness, in which the mine-ness of one's own body is simultaneously an otherness and corporeality is both possessed and dispossessed' (p. 54). In The Stars, this shifting sense of possession and bodily control is allegorical and a key means of communicating psychological instability.

The 'gesture of hysteria' is enacted by Swinton through specific gestures such as feverishly writhing in bed, carving raw chicken and the models' repeated slapping of their own cheeks. Hysteria is also kinaesthetically suggested by the frenzied motion of the characters' bodies, which at times has the appearance of epileptic convulsions and involuntary movements. As demonstrated by the films of Švankmajer and the Quay Brothers, animation plays an important role in creating the illusion of involuntary bodily movements, where it can subversively provoke a sense of the 'gestural uncanny'. In The Stars, pixilation and alternating frame rates create the illusion of involuntary movement closely associated with the cinematic materialisation of hysteria. By fragmenting bodily motion and manipulating the audience's perception of time, Sigismondi re-animates the gestural language of early cinema to reinforce the shifting agencies of 'star' performers, and the psychological instability of celebrity culture.

\section{Transgressions}

In their different ways, each of these case studies has exemplified the volatility of the space inbetween stasis and motion that was demonstrated by Muybridge. They also support Cholodenko's (2014) argument, evincing the cyclic interrelationship between film and live-action animation, death and non-motion. As argued by Caldwell (2000), televisual production steadily became more cinematic during the decades in which Sigismondi's audiovisual aesthetic was in early development. Her music videos have a heightened cinematic feel, which is accentuated by her emphasis on dramatic performance and her inter-textual articulation of gesture. The cinematic quality of her videos may obscure the role of animation in giving (or extracting) life, and estranging the movement of performing bodies. Although the human performers in Sigismondi's videos are neither dead nor inert matter, her puppetisation of their bodies initially renders them as objects. She then gestures through their bodies, liberating their anima in a very controlled manner. This process produces an unstable co-presence of subject and object that is perceived as ontologically ambiguous, and thus labelled as uncanny. Like Švankmajer and the Quays, the animistic evocation of Sigismondi's work is allegorical and subversive. 
Attested to by the 'dancing mannequins' in Montauk Fling, puppetisation and object-ification of the body signify mechanisms of power and control that are taken for granted in society - especially those that construct and regulate gendered behaviour and consumption of the body as a sexualised object. In this way, the movement of these puppetised humans can be understood as transgressing the 'gender order' ${ }^{22}$ The Stars' gesturing hysterics and Montauk Fling's human mannequins rupture the notion of an autonomous body as a free agent of self-expression. In doing so, they pose a challenge to those who equate the consumption of sexualised gesture with beauty, individual expression and feminist agency.

In collaboration with her performers, Sigismondi animates gesture as an act of transgression in a way that is best described by Butler's notion of performative drag. While the instability of Sigismondi's animated figures creates a 'condition of potential detournement', it is gesture's capacity for affective re-iteration and transmutation, as well as its articulatory potential that makes it such a powerful tool for gender transgression (Noland, 2009: 185). Sigismondi does not simply copy and paste gesture onto the surface of bodies. She links gestures from disparate sources, modifies them, re-contextualises them and disperses them into numerous increments of movement. She animates gestures through performing bodies in ways that are not only unpredictable. These bodies are kinaesthetically charged with the potential to detourne the objectified bodies that monopolise music video's performative spotlight.

The use of animation in music video is often equated with novelty and technological innovation. Sigismondi's use of animation may appear novel, but its function is transgressive. Her music videos trangress societal boundaries around gender, beauty, death and religion, as well as the conventions that shape our experience of music video. Her puppetisation of the human body is allegorical, raising questions about the control and agency of embodied subjects in relation to societal power structures and celebrity culture. If her performing bodies appear uncanny or destructive, it is helpful to consider the animistic impulse behind Sigismondi's mantra that 'in order to find ourselves we must destroy ourselves' (Sigismondi, quoted in Robinson, 2013: 2).

\section{Acknowledgements}

I would like to thank Suzanne Buchan as well as the anonymous editors at animation: an interdisciplinary journal for their support and feedback. I would also like to thank Sean Erin Lynch and Bevin Yeatman for providing invaluable conceptual inspiration, as well as Sonya Roussina and Michael de Young for their editorial and technical support.

\section{Funding}

This research received no specific grant from any funding agency in the public, commercial or not-for-profit sectors.

\section{Notes}

1. For an example of puppetised humans in co-presence puppet theatre, see Kate Bredeson's (2002) article 'Human puppets dangling by strings of fate', which discusses Tambours sur la digue, directed by Ariane Mnouchkine and her Theatre du Soleil. Also see 'The co-presence and ontological ambiguity of the puppet' (Piris, 2014).

2. 'Kinesthetic interpolation' refers to the process by which particular aspects of performance can evoke in audience members a bodily sense of empathy with the bodies they are viewing on screen or live performance. This concept is particularly relevant to music video, dance and sporting performance (Reynolds and Reason, 2012).

3. Examples of such images include Adam Jones's stop motion puppet animation in his video for Tool's song Prison Sex (1994), Chris Cunningham's robotic representation of Bjork in All Is Full of Love (1999), 
Michel Gondry's puppetised band performance in the video for The Vines' song Anysound (2006), and Chris Hopewell's pixilated representation of Thom Yorke in his video for Radiohead's song There There (2003).

4. Sigismondi's music videos blur the boundaries between the formal conventions of music video and film. This is exemplified in her music video for The Stars (Are Out Tonight) (2013), which uses the film convention of titles that introduce the star characters followed by 'A Film by Floria Sigismondi'. This video also includes sections of characters' dialogue, incorporates a 'film style look' and uses intertextual film references, such as the magazine cover image from The Man Who Fell to Earth (1976, director Nicholas Roeg). Similar blurring of formal conventions can be seen in her 'music short film' Leaning Towards Solace (2012) for Sigur Ros's music short competition.

5. The strategy of 'ostranenie' (estranging the familiar) was developed by Viktor Shklovskij, and is discussed by Crawford (1984).

6. For an explanation of the zoopraxiscope and other 19th-century optical technologies, see 'The first zoopraxiscope disc: The first motion picture?' in Prodger (2003: 154-161).

7. The co-presence of pixilation alongside object animation can be seen in a number of Švankmajer's feature-length and short films. The most prominent examples are Alice (1988), The Flat (1968) and Food (1992).

8. The complexity of music video's representations of the female body is discussed by Railton and Watson (2011). Since the writing of that publication, the performativity of gestures that objectify the female body have proliferated in popular music video, distributed predominantly via viral media sharing. The dance gesture known as 'twerking' has been used provocatively by Miley Cyrus at the 2013 MTV Video Music awards. Since then associated gestures have been performed, most notably in music videos such as Wrecking Ball directed by Terry Richardson for Myley Cyrus (2013), Anaconda, directed by Colin Tilley for Nicki Minaj (2014) and Booty, directed by Hype Williams for Jennifer Lopez (2014). These performative acts have generated the production of parodies and have provoked extensive debate about the origin, ownership and function of such gestures, particularly in relation to feminist discourse.

9. In his article 'Presenting death: Uncanny performing objects in Taduesz Kantor's Dead Class', Jacob Juntunen (2012) discusses the uncertainty of subject and object in relation to human puppetry and object theatre.

10. For examples of those who argue that the uncanny valley obstructs empathetic identification, see Pollick (2010) and Theodore (2004).

11. Emma Westecott (2009: 5) argues that the quest for digital realism 'stands in contradiction' to her exploration of the creative possibilities of considering digital game-play as a form of puppetry.

12. The human puppets in the theatre production Tambours sur la digue, directed by Ariane Mnouchkine and her Theatre du Soleil, demonstrated this lack of sentience. A discussion of how this phenomenon plays out in this production can be found in 'Human puppets dangling by strings of fate' (Bredeson, 2002).

13. Such sources include silent film, pixilated film, puppet animation, surrealist film, avant-garde art, art and fashion photography, dance, theatrical costumes and sets, celebrity culture, shop mannequins and more.

14. 'Although the conventional fashion pose may have little to do with real-world actions, it is nonetheless part of a lexicon that provides a context and identifies it as a pose' (Shinkle, 2013: 81).

15. Cindy Sherman's Untitled Film Stills (1977-1980) are particularly relevant to Montauk Fling, as well as other work of Sigismondi. For a discussion of the way Sherman's work engages with stasis and motion and her articulation of cinematic references within her still photography, see Baker (2005).

16. Automaton-like characters gesturing (im)mobility and (de)animation are exemplified in Sigismondi's music videos for Marilyn Manson's songs The Beautiful People (1999) and Tourniquet (1999). Sigismondi discusses her conceptual development of these videos in an interview with Carol Vernallis and Hannah Ueno (2013).

17. These 'analogical gestures' of hysteria are described in detail by Crow (2006: 53): 'the woman and the doll each have a disturbingly spastic twitching finger.'

18. Rothman closely studied the film Dracula (1992) to prepare for his performance in Montauk Fling (Nowness.com, 2013). 
19. There are many examples of lipstick smearing as an act of performative drag: David Bowie performed the backhanded lipstick smear in drag in the music video for Boys Keep Swinging (see: http://thequietus.com/articles/03161-30-years-on-david-bowie-s-lodger-comes-in-from-the-cold). This gesture was re-performed by Geeling Ching in Bowie's music video for China Girl, and more recently by Lorde at the American Music Awards (see: http://www.nzherald.co.nz/entertainment/news/article.cfm?c $\mathrm{id}=1501119$ \&objectid=11366449). Celebrities have promoted the act of lipstick smearing in support of the SmearForSmear campaign, which is aimed at raising awareness of the need to have regular cervical smears (https://storify.com/Women24/the-smearforsmear).

20. These performers include the music, the director, the animated bodies of human actors, puppets, dolls and mannequins, and the cinematic body of the music video.

21. The models in The Stars music video are played by Andreja Pejic and Saskia de Brauw. Iselin Steiro performs drag of Bowie's persona 'The Thin White Duke'.

22. The 'gender order' has been described as 'the repressive ideology that ensures that deviation from gender norms (by women and men) entails penalties ... language plays an important part in constructing the gender order' (Holmes and Marra, 2010: 2).

\section{References}

Auerbach J (2007) Body Shots: Early Cinema's Incarnations. Berkeley: University of California Press.

Baker J (2005) Photography's expanded field. October 114, Fall: 120-140.

Baron S and Carnicke SM (2008) Reframing Screen Performance. Ann Arbor: University of Michigan Press. Bell J (2014) Playing with the eternal uncanny: The persistent life of lifeless objects. In Posner DN et al. (eds)

The Routledge Companion to Puppetry and Material Performance. Abingdon: Routledge, 43-52.

Brannigan E (2011) Dancefilm: Choreography and the Moving Image. New York: Oxford University Press.

Bredeson K (2002) Human puppets dangling by strings of fate. Theater: The Yale School of Drama/Yale Repertory Theatre 32(3): 138-143.

Buchan S (2011) The Quay Brothers: Into a Metaphysical Playroom. Minneapolis: University of Minnesota Press.

Butler J (1990) Gender Trouble: Feminism and the Subversion of Identity. New York: Routledge.

Caldwell JT (2000) Modes of production: The televisual apparatus. In: Stam R, Miller T (eds) Film and Theory: An Anthology. Malden, MA: Blackwell, 125-143.

Cardinal R (1995) Thinking through things: The presence of objects in the early films of Jan Švankmajer. In: Hames P (ed.) Dark Alchemy: The Films of Jan Švankmajer. Trowbridge: Flicks Books, 78-95.

Cholodenko A (2014) 'First principles' of animation. In: Beckman K (ed.) Animating Film Theory. Durham, NC: Duke University Press, 98-110.

Colman F (2011) Deleuze and Cinema: The Film Concepts. New York: Berg.

Crawford L (1984) Viktor Shklovskij: Difference in defamiliarization. Comparative Literature 36: 209 219.

Crow H (2006) Gesturing toward Olympia. In: Buchan S (ed.) Animated 'Worlds'. Eastleigh: John Libbey, 49-62.

De Barros A (a) An interview with Floria Sigismondi. In SCENE: 360. Available at: www.habermas.org/ interview-floria1.html (accessed 16 December 2014).

De Barros A (b) Review. In SCENE 360. Available at: http://www.csudh.edu/dearhabermas/ARTdirect FloriaSigismondi.html (accessed 16 December 2014).

Fresko D (2013) Muybridge's magic lantern. animation: an interdisciplinary journal 8(1): 47-67.

Furniss M (1998) Art in Motion: Animation Aesthetics. Orange, CA: Chapman University School of Film and Television.

Holmes J and Marra M (eds) (2010) Femininity, Feminism and Gendered Discourse: A Selected and Edited Collection of Papers from the Fifth International Language and Gender Association Conference (IGALA5). Newcastle upon Tyne: Cambridge Scholars Publishing.

Ivins-Hulley L (2013) A universe of boundaries: Pixilated performances in Jan Švankmajer's Food. animation: an interdisciplinary journal 8(3): 267-282. 
Jentsch E (1995[1906]) Document: On the psychology of the uncanny, trans. R Sellars. Angelaki 2(1): 17-21 (reprinted in Collins J, Jervis J (eds) (2008) Uncanny Modernity: Cultural Theories, Modern Anxieties. London: Palgrave Macmillan).

Juntunen J (2012) Presenting death: Uncanny performing objects in Taduesz Kantor's 'Dead Class'. Puppetry International 31, Spring/Summer: 14-18.

Mulvey L (2006) Death $24 x$ a Second, Stillness and the Moving Image. London: Reaktion Books.

Noland C (2009) Agency and Embodiment: Performing Gestures/Producing Culture. Cambridge, MA: Harvard University Press.

Nowness.com (2013) Lawrence Rothman: Montauk Fling. Floria Sigismondi takes to Las Chateau Marmont for a tale of glamour and madness. Available at: https://www.nowness.com/story/lawrence-rothmanmontauk-fling (accessed 16 December 2014).

Papenburg B and Zarzycka M (eds) (2013) Carnal Aesthetics: Transgressive Imagery and Feminist Politics. London: IB Tauris.

Piris P (2014) The co-presence and ontological ambiguity of the puppet. In: Posner DN et al. (eds) The Routledge Companion to Puppetry and Material Performance. Abingdon: Routledge, 30-42.

Pollick FE (2010) In Search of the Uncanny Valley. Lecture Notes of the Institute for Computer Sciences. Social Informatics and Telecommunications Engineering 40(4): 69-78.

Prodger P (ed.) (2013) Time Stands Still: Muybridge and the Instantaneous Photography Movement. New York: Oxford University Press.

Railton D and Watson P (2011) Music Video and the Politics of Representation. Edinburgh: Edinburgh University Press.

Reynolds D and Reason M (eds) (2012) Kinesthetic Empathy in Creative and Cultural Practices. Bristol: Intellect.

Robinson M (2013) Interview with Floria Sigismondi. Available at: http://michaelrobinsonnyc.com/ blog/2013/5/28/nude-magazine (accessed 16 December 2014).

Rotman B (2008) Becoming Beside Ourselves: Alphabet, Ghosts, Distributed Human Beings. Durham, NC: Duke University Press.

Shinkle E (2013) Uneasy bodies: Affect, embodied perception and contemporary fashion photography. In: Papenburg B, Zarzycka M (eds) Carnal Aesthetics: Transgressive Imagery and Feminist Politics. London: IB Tauris, 73-88.

Simms EM (1996) Uncanny dolls: Images of death in Rilke and Freud. New Literary History 27(4): 663-677.

Sobchack V (1992) The Address of the Eye: a Phenomenology of Film Experience. Princeton, NJ: Princeton University Press.

Stern L (2002) Putting on a show, or the ghostliness of gesture. Lola Journal. Available at: http://www.lolajournal.com/5/putting_show.html (accessed 2 February 2015).

Theodore S (2004) Uncanny valley. Game Developer 11(11): 43-45.

Tinwell A (2014) The Uncanny Valley in Games and Animation. Boca Raton, FL: CRC Press/ Taylor and Francis.

Vernallis C (2004) Experiencing Music Video: Aesthetics and Cultural Context. New York: Columbia University Press.

Vernallis C (2013) Unruly Media: Youtube, Music Video, and the New Digital Cinema. New York: Oxford University Press.

Vernallis C and Ueno H (2013) Interview with music video director and auteur Floria Sigismondi. Music, Sound, and the Moving Image 7(2), Autumn: 167-194.

Wells P (1998) Understanding Animation. London: Routledge.

Westecott E (2009) The player character as performing object. Breaking New Ground: Innovation in Games, Play, Practice and Theory. Proceedings of DiGRA 2009: 1-6.

Wood A (2006) Re-animating space. animation: an interdisciplinary journal. 1(2): 133-152.

\section{Music videos and films cited}

All Is Full of Love (1999) Music video for Bjork, directed by Chris Cunningham Anysound (2006) Music video for The Vines, directed by Michel Gondry 
Being John Malkovich (1999) Directed by Spike Jonze

Blue Velvet (1986) Directed by David Lynch

Dracula (1992) Directed by Francis Ford Coppola

End of the World (2004) Music video for The Cure, directed by Floria Sigismondi.

Food (1992) Directed by Jan Švankmajer

Little Wonder (1996) Music video for David Bowie, directed by Floria Sigismondi

Montauk Fling (2013) Music video for Lawrence Rothman, directed by Floria Sigismondi

Prison Sex (1994) Music video for Tool, directed by Adam Jones

Street of Crocodiles (1986) Directed by Stephen and Timothy Quay

The Club of the Laid Off (Klub odlozenych) (1989) Directed by Jiri Barta

The Comb (1991) Directed by Stephen and Timothy Quay

The Flat (1968) Directed by Jan Švankmajer

The Sandman (2000) Directed by Stephen and Timothy Quay

The Stars (Are Out Tonight) (2013) Music video for David Bowie, directed by Floria Sigismondi

There There (2003) Music video for Radiohead, directed by Chris Hopewell

Who's Afraid of Virginia Woolf? (1966) Directed by Mike Nichols

Wild at Heart (1990) Directed by David Lynch

\section{Author biography}

Lisa Perrott is Senior Lecturer at the University of Waikato. Her teaching and research cuts across animation, visual music, music video, performativity and gender representation. Lisa directed the stop motion short film animascope (2010) and has collaborated with musicians and dancers on cross-platform performances and curated exhibitions, including the moving image show for the exhibition Mind Games: Surrealism in Aotearoa (2009). In 2011 she curated the exhibition Handmade Pixels: Exposing the Animation Process, and directed the international symposium Animating Time-Space. 